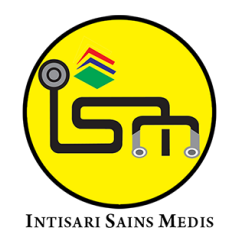

Published by Intisari Sains Medis

\section{The effect of Modified Radical Mastectomy (MRM) with and without latissimus dorsi flap on seroma of Locally Advanced Breast Cancer (LABC) in Sanglah Hospital}

'Department of General Surgery, Faculty of Medicine, Universitas Udayana, Sanglah General Hospital, Bali, Indonesia;

${ }^{2}$ Department of Surgical Oncology, Faculty of Medicine, Universitas Udayana, Sanglah General Hospital, Bali, Indonesia;

${ }^{3}$ Department of Internal Medicine, Faculty of Medicine, Universitas Udayana, Sanglah General Hospital, Bali, Indonesia;

*Corresponding author: Anak Agung Tedy Pramana;

Department of General Surgery, Faculty of Medicine, Universitas Udayana, Sanglah General Hospital, Bali, Indonesia;

tedy.zion@gmail.com

Received: 2021-06-12

Accepted: 2021-07-28

Published: 2021-08-10
Anak Agung Chris Tedy Pramana ${ }^{1 *}$, I Ketut Widiana ${ }^{2}$, I Gde Raka Widiana ${ }^{3}$

\section{ABSTRACT}

Background: Locally Advanced Breast Cancer (LABC) is defined as breast cancer spread locoregionally and without any signs of metastasis. Stage IIIA breast cancer is one type of $L A B C$ that can be removed surgically, and Modified Radical Mastectomy (MRM) remains the first surgical option. Seroma production is one of the most common complications post MRM, with the hypothesis stating that the Latissimus Dorsi (LD) flap technique is responsible for resulting in higher seroma output. This study aims to compare seroma production in $L A B C$ patients post MRM with and without LD flap.

Methods: This prospective cohort study was conducted in Sanglah General Hospital, Denpasar, between November 2018 and January 2020. The study sample was divided into 2 groups: LABC patients post MRM with and without LD flap reconstruction. Seroma was measured in milliliters $(\mathrm{ml})$ and collected from the first to fifth day post-operation. Data were analyzed using SPSS version 21 for Windows.

Results: Forty $L A B C$ patients were enrolled in this study. The mean age for the group without latissimus dorsi flap was $48.45 \pm 7.01$ years and $49.40 \pm 10.77$ years for the group with latissimus dorsi flap. The mean seroma production in $L A B C$ patients who underwent MRM without and with LD flap reconstruction was $696.45 \pm 66.37 \mathrm{ml}$ and $490.10 \pm 62.11 \mathrm{ml}$. There was a significant difference in the total of seroma between the treatment group without-LD flap and compared to with-LD flap reconstruction $(p<0.001)$.

Conclusion: Seroma production is significantly higher in $L A B C$ patients post MRM without LD flap reconstruction than $\angle A B C$ patients with $L D$ flap.
Keywords: Locally Advanced Breast Cancer, Latissimus Dorsi Flap, Seroma.

Cite This Article: Pramana, A.A.C.T., Widiana, I.K., Widiana, I.G.R. 2021. The effect of Modified Radical Mastectomy (MRM) with and without latissimus dorsi flap on seroma of Locally Advanced Breast Cancer (LABC) in Sanglah Hospital. Intisari Sains Medis 12(2): 572-575. D0l: 10.15562/ism.v12i2.1059

\section{INTRODUCTION}

Locally Advanced Breast Cancer (LABC) is defined as breast cancer spread in locoregional but does not spread beyond the breast and regional lymph nodes. ${ }^{1}$ Furthermore, breast cancer is classified into LABC type when it has a large lump size, defect on the breast skin and/or the muscle under the breast toward the thoracic wall, and has infiltrated the local lymph nodes. ${ }^{2}$ According to the TNM system by the American Joint Committee on Cancer, LABC is defined as stage III, which can be represented as stage IIIA, IIIB, and IIIC. ${ }^{3}$ Surgery is the main treatment option for breast cancer, and the modified radical mastectomy (MRM) is the treatment of choice for operable breast cancer. ${ }^{4}$ Postsurgical complications include hematoma, seroma formation, surgical wound infection, up to the formation of a necrotic flap. ${ }^{5}$

Seroma is defined as a serous fluid formed after surgery, under the skin flap, and collected in the dead space. ${ }^{6}$ Several hypotheses stated that surgery disrupts the lymphatic channels, resulting in a collection of fluid, which is seroma. This hypothesis is supported by a study that said latissimus dorsi (LD) flap has a higher risk of seroma formation than without LD flap. ${ }^{7}$ The accumulation of seroma fluid increases and lifts from the lining of the chest wall and axillary to the tissue. ${ }^{8}$ Seroma can make the patient anxious, causes discomfort, and disrupt wound healing. These reasons might cause necrotic flap, infection, hematoma, delayed wound healing, prolonged hospitalization, and increased treatment costs. Based on those mentioned above, this study aims to determine the role of LD flap on seroma for postsurgical MRM LABC patients.

\section{METHODS}

This study is an observational-analytic with a cohort-retrospective design. This study analyzed the mean seroma production of operable LABC patients and compared the seroma production of operable LABC patients to MRM with and without LD flap. This study was conducted in Sanglah General Hospital (RSUP), the main referral hospital in the Bali province located in the West Denpasar, 
Bali, and is the Faculty of Medicine, Universitas Udayana Hospital. This study was conducted from November 2018 until January 2020 by the Department of Surgical Oncology Faculty of Medicine, Universitas Udayana, Bali, Indonesia. The inclusion criteria were all postsurgical MRM LABC patients, reconstructed with and without LD flap in Sanglah Hospital, and willing to participate in the study. The sampling method was consecutive sampling, in which all patients presented and met the inclusion and exclusion criteria are included in the study until the required subjects are met.

This study was conducted after fulfilling the ethical feasibility according to the Research Ethical Committee of the Faculty of Medicine, Universitas Udayana, Sanglah Hospital, and fulfilling the study requirements by the Director of Sanglah Hospital. Both patients with and without LD flap reconstruction were observed for their collected seroma in the postsurgical drain. The total amount of seroma was calculated up to the fifth postoperative day. Seroma production was counted in milliliters and was a numeric variable. Data analysis was divided into 2 parts, descriptive and bivariate analysis. Both means of seroma production were compared using the data normalization test, Shapiro Wilk, and the homogeneity of data by Levene test. If the data is normally distributed and the variants are homogenous, a parametric independent T-test is performed. If the data is not normally distributed, the Mann-Whitney $\mathrm{U}$ test is performed. The result was considered significant if the $\mathrm{p}$-value $<0.05$ and CI 95\%. All of the data processing was carried out using the Statistical Program for Social Science (SPSS) version 21 for Windows.

\section{RESULTS}

This study involved 40 LABC patients in determining the difference between the incidence rate of seroma post-MRM with and without LD flap. Table 1 described the characteristics of participants based on age. The mean age for the group without LD flap was $48.45 \pm 7.01$ years and for the group with LD flap, $49.40 \pm 10.77$ years (Table 1). The mean total seroma for LABC patients with MRM without LD flap

Table 1. Baseline characteristics of participants

\begin{tabular}{lcc}
\hline \multirow{2}{*}{ Variable } & \multicolumn{2}{c}{ MRM approach (N=40) } \\
\cline { 2 - 3 } & Without LD flap (N=20) & With LD flap (N=20) \\
\hline Age (Years) (mean \pm SD) & $48.45 \pm 7.01$ & $49.40 \pm 10.77$ \\
Total seroma (ml) $($ mean \pm SD) & $696.45 \pm 66.37$ & $490.10 \pm 62.11$ \\
\hline
\end{tabular}

MRM: Modified Radical Mastectomy; SD: Standard Deviation; LD: Latissimus Dorsi

\section{Table 2. The difference in the total of seroma between treatment group without-latissimus dorsi flap and compared to with-latissimus dorsi flap}

\begin{tabular}{ccccc}
\hline $\begin{array}{c}\text { Total of seroma } \\
(\mathbf{m l})\end{array}$ & Mean \pm SD & $\begin{array}{c}\text { Mean Difference } \\
\text { (MD) }\end{array}$ & $\mathbf{9 5 \% ~ C l}$ & p \\
\hline $\begin{array}{c}\text { Without LD flap } \\
\text { With LD flap }\end{array}$ & $\begin{array}{c}696 \pm 66 \\
490 \pm 62\end{array}$ & $207 \pm 20$ & $165-247$ & $<0.001^{\star}$ \\
\hline
\end{tabular}

SD: Standard Deviation; CI: Confidence Interval; ${ }^{\star}$ Independent T-test: Statistically significant if p-value less than 0.05 .

was $696.45 \pm 66.37 \mathrm{ml}$ and $490.10 \pm 62.11$ $\mathrm{ml}$ for LABC patients with MRM with LD flap (Table 1).

The next analysis was to determine the difference in the mean seroma between the treatment groups without LD flap and with LD flap. Several tests, including data normalization and homogeneity, were conducted. On Shapiro Wilk, the p-value for total seroma was 0.498 ( $p>0.05$ ), which means the data was normally distributed. Levene's test for homogeneity showed a $p$-value was 0.633 ( $p>0.05)$, which means the data was homogenous. The difference in mean between treatment groups without and with LD flap was analyzed using an independent T-test (Table 2).

Table 2 reflected the independent T-test analysis results. The mean difference between the group without LD flap and with LD flap was $207 \mathrm{ml}$ with a p-value of 0.001 . This result showed a significant difference between treatment without LD flap and with LD flap. The mean total seroma of LABC patients who underwent MRM without latissimus dorsi flap $(696 \pm 66 \mathrm{ml})$ was higher than that of the

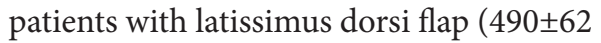
ml) (Table 2).

\section{DISCUSSION}

According to World Health Organization data, the frequency and mortality of breast cancer have increased substantially in developing countries. Although breast cancer incidence has increased, the overall first 5-year survival rate for breast cancer has reached $100 \%$, and the second phase has reached $93 \%$ due to early detection of the disease and advanced treatment methods. The increased life expectancy has helped provide a better cosmetic appearance of the breast and led to an increased rate of breast-conserving surgery. ${ }^{9,10}$

This study result showed that the mean age of LABC patients with MRM without LD flap was $48.45 \pm 7.01$ years old. This result was not significantly different from the mean age of LABC patients with MRM with LD flap, $49.40 \pm 10.77$ years old. This study result is in accordance with the study by Duymaz $T$ et al., that stated the mean age of the patient who underwent mastectomy was between $47-48$ years old. ${ }^{9}$ The study by Ibraheem $\mathrm{MH}$ et al., said different characteristics, in which the mean age of the patients who underwent LD flap was 41.4 years old. ${ }^{11}$ When viewed in terms of age, the incidence rate of breast cancer varies according to the patient's age range, and the range of 40-69 years old has the highest incidence rate of $90 \%{ }^{12} \mathrm{~A}$ different study result by Kokosis $\mathrm{G}$ et al., stated that the mean age of patients who underwent breast reconstruction with LD flap was 53.2 years old. ${ }^{13}$

Based on the characteristics of the total seroma in this study, the mean total seroma of LABC patients who underwent MRM without LD flap was 694.45 milliliter, 
which was more than the mean total seroma LABC patients who underwent MRM with latissimus dorsi flap (mean of 490.10 milliliters). This result is not in line with the study by Burgic $\mathrm{M}$ et al., which stated that LD flap has a higher risk of seroma formation compared to without LD flap. ${ }^{7}$ Seroma can occur in the postoperative period. Seroma occurs due to the uneven surgical wound between one section and the others. ${ }^{7,8}$ On that account, the surgical team would apply a drainage tube in the body for several hours or days in the postoperative period. The goal is, indeed, to stop the collecting of the fluid. In some cases, an inserted drainage tube would be sufficient to prevent seroma based on the previous study. ${ }^{14}$

Our study result showed a significant effect of MRM without LD flap and with LD flap on the total seroma. MRM treatment without LD flap increased the occurrence of seroma in LABC patients. A study result by Houvenaeghel $G$ et al., of 16 breast cancer patients who underwent Robotic Latissimus DorsiFlap Reconstruction (RLDFR) stated that RLDFR was feasible, safe, and can be done, especially in reducing the duration of the surgery, postoperative length of stay, and complication rates. ${ }^{15}$ The decline in shoulder function causes shoulder movement that is performed after prolonged immobilization. A study by Sampathraju $S$ et al., supported this theory that early active shoulder movements after surgery have a higher incidence of seroma formation than shoulder movements that are performed later on. ${ }^{16}$ A study by Ibraheem $\mathrm{MH}$ et al. stated that the cosmetic drawbacks of breast-conserving surgery are asymmetry, nipple or skin retraction, and loss of volume, which results in unsatisfactory cosmetic results. ${ }^{11}$

LD flap is an essential reconstruction method of choice due to its stability and flexibility as an autologous flap. However, some of the disadvantages of the flap are associated with additional donor sites with scarring and potential morbidity. The disadvantages of the LD flap would include seroma, a dilated scar that occurs at the donor site secondary to the increased tension in the healing dermis, and poor wound healing on the donor site if there was too much soft tissue removed. In a study by Ibraheem $\mathrm{MH}$ et al., about 15 patients had donor site seroma. ${ }^{11}$ The study result by Lee JS et al., who performed breast reconstruction with LD flap in January 2014 until June 2018 with 275 cases, stated that there were 3 cases of hematoma developed after breast reconstruction with LD flap. ${ }^{17}$ Although previous studies had indicated seroma as the most common complication, the incidence of hematoma in a few years after surgery is rarely reported late. Chronic hematomas may occur when the tissue is damaged from shear forces generated due to stress, which consequently induces bleeding, followed by poor coagulation. ${ }^{10}$

\section{CONCLUSION}

It can be concluded that there is a difference in the mean of total seroma in LABC patients with MRM with and without LD flap. The different treatments affect the total seroma. The treatment without LD flap increases the amount of seroma, while the treatment decreases the amount of seroma. To our knowledge, we had not yet found another study that compares the incidence of seroma between LABC patients who underwent MRM without latissimus dorsi and with latissimus dorsi. Therefore, we hope that this study can be used as the basis for further studies related to the incidence of seroma in LABC patients who underwent MRM.

\section{CONFLICT OF INTEREST}

The authors report no conflicts of interest regarding this study.

\section{ETHICS CONSIDERATION}

Ethics approval has been obtained from the Ethics Committee, Faculty of Medicine, Universitas Udayana, Sanglah General Hospital, Bali, Indonesia, prior to the study being conducted.

\section{FUNDING}

None.

\section{AUTHOR CONTRIBUTIONS}

All authors equally contribute to the study from the conceptual framework, data acquisition, data analysis, and reporting the study results through publication.

\section{REFERENCES}

1. Simos D, Clemons M, Ginsburg OM, Jacobs C. Definition and consequences of locally advanced breast cancer. Curr Opin Support Palliat Care. 2014;8(1):33-38.

2. Spitale A, Mazzola P, Soldini D, Mazzucchelli L, Bordoni A. Breast cancer classification according to immunohistochemical markers: clinicopathologic features and short-term survival analysis in a population-based study from the South of Switzerland. Ann Oncol. 2009;20(4):628-635.

3. Edge SB, Compton CC. The American Joint Committee on Cancer: the 7th edition of the AJCC cancer staging manual and the future of TNM. Ann Surg Oncol. 2010;17(6):1471-1474.

4. Ribeiro GH, Kerr LM, Haikel RL, Peres SV, Matthes AG, Depieri Michelli RA, et al. Modified radical mastectomy: a pilot clinical trial comparing the use of conventional electric scalpel and harmonic scalpel. Int J Surg. 2013;11(6):496-500.

5. Vitug AF, Newman LA. Complications in breast surgery. Surg Clin North Am. 2007;87(2):431451.

6. Ebner F, Friedl TWP, de Gregorio A, Lato K, Bekes I, Janni W, et al. Seroma in breast surgery: all the surgeons fault? Arch Gynecol Obstet. 2018;298(5):951-959.

7. Burgic M, Bruant Rodier C, Wilk A, Bodin F, Rifatbegović A, Halilbasic E, et al. Complications following autologous latissimus flap breast reconstruction. Bosn J Basic Med Sci. 2010;10(1):65-7.

8. Kuroi K, Shimozuma K, Taguchi T, Imai H, Yamashiro H, Ohsumi S, et al. Evidence-based risk factors for seroma formation in breast surgery. Jpn J Clin Oncol. 2006;36(4):197-206.

9. Duymaz $\mathrm{T}$, İyigün $\mathrm{ZE}$, İlgün AS, Ordu Ç, Üçüncü M, Alço G, et al. The Effect of MiniLatissimus Dorsi Flap (MLDF) Reconstruction on Shoulder Function in Breast Cancer Patients. Eur J Breast Health. 2019;15(3):158-162.

10. Millikan RC, Newman B, Tse CK, Moorman PG, Conway K, Dressler LG, et al. Epidemiology of basal-like breast cancer. Breast Cancer Res Treat. 2008;109(1):123-39.

11. Ibraheem MH, Mina MG, Youssef YA, Boutrus R, Farouk A, Morsi A. The use of latissimus dorsi mini-flap in partial breast reconstruction. J Cancer Sci Clin Ther. 2019;3(4):240-250.

12. Quaresma M, Coleman MP, Rachet B. 40-year trends in an index of survival for all cancers combined and survival adjusted for age and sex for each cancer in England and Wales, 1971-2011: a population-based study. Lancet. 2015;385(9974):1206-1218.

13. Kokosis G, Khavanin N, Nahabedian MY. Latissimus Dorsi Musculocutaneous Flap for Complex Breast Reconstruction: Indications, Outcomes and a Proposed Algorithm. Plast Reconstr Surg Glob Open. 2019;7(8):e2382. 
14. Gonzalez EA, Saltzstein EC, Riedner CS, Nelson BK. Seroma formation following breast cancer surgery. Breast J. 2003;9(5):385-388.

15. Houvenaeghel G, Bannier M, Rua S, Barrou J, Heinemann M, Lambaudie E, et al. Skin sparing mastectomy and robotic latissimus dorsi-flap reconstruction through a single incision. World J Surg Oncol. 2019;17(1):176.
16. Sampathraju S, Rodrigues G. Seroma formation after mastectomy: pathogenesis and prevention. Indian J Surg Oncol. 2010;1(4):328333.

17. Lee JS, Jeon HJ, Lee J, Park HY, Yang JD. Treatment of late solidified hematoma in back donor site after breast reconstruction with latissimus dorsi flap: report of three cases. BMC Surg. 2019;19(1):51.

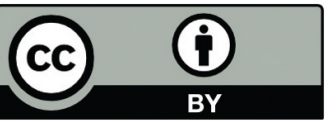

This work is licensed under a Creative Commons Attribution 